\title{
Three-Minute Herbal Treatment to Reduce Dental Caries with a Newbouldia laevis Based Extract
}

\author{
Amaechina Okechukwu Okeke \\ Department of Botany \\ University Of Ibadan \\ Ibadan, Oyo State Nigeria
}

Received March 13, 2002 Accepted June1, 2003

\begin{abstract}
An extract made from leaves of the tree Newbouldia laevis was tested as a bactericide for the bacteria implicated in dental caries. Thirty toothache patients used the extract as a mouthwash and the mouthwash's bactericidal action was tested under laboratory conditions. Bacterial action was arrested in 25 of the 30 patients.
\end{abstract}

\section{INTRODUCTION}

Toothache is the condition in which severe pain is experienced in the region near the root of a carious tooth. Dental caries (tooth decay) is the result of a progressive destruction of tooth enamel by bacteria and bacterial products within the oral environment. Oral pain occurs as a result of bacterial activity in the pulp of a carious tooth.

Two bacteria types have been implicated in caries formation: Streptococci mutans and Lactobacilli. Streptococci mutans produces an enzyme dextransucrase, which converts the sucrose of food to dextrin, and dextrin combines with salivary proteins to create a sticky, colorless film (plaque) on tooth surfaces. Plaque provides the haven for the activities of Lactobacilli and these produce of lactic acid, which attacks the enamel by decalcifying it.

The use of plants as medicine is an ancient practice common to all societies. However, the knowledge of the appropriate medicinal application of plants is still a bit mysterious. One ancient way of obtaining this knowledge was to look for "natural signatures". These were shapes and patterns in plant organs similar in shape or pattern to organs of the animal (human) body. The pattern of venation in the fully matured leaves Newbouldia laevis gives the impression of a rough tooth-like grinding surface. The general appearance of the leaves gives the same impression. This has been sufficient for some in the folk medicine community to suggest these leaves as a treatment for toothache.

Newbouldia laevis or Boundary Tree is a medium sized angiosperm in the Bignoniaceae family. It is native to tropical Africa, and grows to a height of about 10 meters. The tree flowers in spring and summer with a cauliferous habit, meaning that it bears flowers on its trunk. It is evergreen, though its leaves turn somewhat dark purple during the winter months [1]. Leaves of Newbouldia laevis contain a class of indole alkaloids called beta-carbolines [2].

In this report, I shall discuss a test for an extract prepared from the fully matured leaves of Newbouldia laevis as a bactericide against those microbes implicated in causing toothache. The laboratory investigation is directed to discovering the effects of a Newbouldia laevis based extract on toothache causing microbes. 


\section{PREPARATION AND APPLICATION}

An extract of Newbouldia laevis was prepared by boiling the plant's dried leaves in sterile water. The result was an extract that was suspended in water, with a brownish, moderately turbid appearance. This liquid was then prepared as a mouthwash for human consumption. To determine the medical effect of this mouthwash, people with toothaches were chosen to ensure an adequate supply of dental-caries-causing bacteria of the type described in the introduction.

Thirty toothache patients in this study began by rinsing their mouths with sterile water. After this, they rinsed their mouths with the mouthwash for exactly three minutes before spitting the mouthwash into sterile containers. The patients' mouthwash samples were then inoculated onto growth media (four separate media for each patient sample), and then were incubated for several days (detailed in the Methods section). The laboratory protocols for incubating and examining the samples are now addressed.

\section{METHODS}

a. Inoculation

Every specimen was aseptically inoculated, using a wire loop, onto 4 different microbial propagation media used for isolation of a wide range of bacterial and yeast-like infections:

(i) The entire length of the wire loop was flamed to incandescence beginning by positioning the end of the wire loop in the cool (blue) cone of flame initially. It was then allowed to cool.

(ii) The cover of each specimen container was opened and inoculums collected and covers properly replaced. The cover of each petri dish was opened and the growth medium inoculated.

(iii) Streaking was done three times on each growth medium with flaming and cooling of the wire loop in between the streakings. Subsequent streaking after the inoculation overlapped the first original streaking (the inoculation). The wire loop was then flamed to sterilize it.

Inoculation onto growth media was done within ten minutes of collecting the mouthwash from patients. As mentioned in (ii) and (iii), all processes were done within the heat field of the Bunsen burner flame.

b. Incubation

The different inoculated culture plates were incubated under the following conditions:

(i) Blood Agar: Aerobic condition or Oxygen $\left(\mathrm{O}_{2}\right)$ rich atmosphere with 30 hours to 48 hours of incubation at $37^{\circ} \mathrm{C}$.

(ii) Desoxycholate lactose Agar: Aerobic condition or oxygen rich atmosphere with 30hours to 48hours of incubation at $37^{\circ} \mathrm{C}$.

(iii) Chocolate Agar: Anaerobic condition or carbon dioxide $\left(\mathrm{CO}_{2}\right)$ atmosphere with 30 hours to 48 hours of incubation at $37^{\circ} \mathrm{C}$

(iv) Sabouraud dextrose Agar: Aerobic condition with 120 hours to 168 hours of incubation at room temperature of about $25^{\circ} \mathrm{C}-30^{\circ} \mathrm{C}$.

c. Microscopic Examination

Upon arrival to the lab a direct smear of each specimen was prepared as follows:

(i) A smear of specimen was made and fixed by gentle heating.

(ii) A smeared slide was flooded with crystal violet and allowed to react for one to two minutes.

(iii) Lugol's iodine was used to flood the slide (after excess primary stain was poured away) and allowed to react for one minute.

(iv) The slide was washed with distilled water, decolorized with $95 \%$ alcohol and then counterstained with dilute carbolfushion solution for thirty seconds to one minute.

(v) It was than washed with water dried and finally examined microscopically 
using 100-power oil immersion objective.

\section{RESULTS}

a. Identification of Isolates

Five out of the thirty patients produced mouthwash specimens that yielded microbial growth, namely specimens $2,3,5,8$, and 27 . The microbial-positive samples from these five patients comprised 7 of the 120 cultured petri dishes. The microorganisms were identified using gram stain examination and colony characteristics.

\begin{tabular}{|l|l|}
\hline $\begin{array}{c}\text { Microorganisms } \\
\text { Isolated }\end{array}$ & \multicolumn{1}{|c|}{$\begin{array}{c}\text { Colony } \\
\text { Characteristics }\end{array}$} \\
\hline $\begin{array}{l}\text { Staphylococci } \\
\text { aureus }\end{array}$ & $\begin{array}{l}\text { Golden color, 2 mm in } \\
\text { diameter, raised with } \\
\text { entire edge. }\end{array}$ \\
\hline Streptococci spp & $\begin{array}{l}\text { Gray-white color, 1 } \\
\mathrm{mm} \text { in diameter, with } \\
\text { Alpha hemolysis. }\end{array}$ \\
\hline Candida albicans & $\begin{array}{l}\text { Light gray in color, 5 - } \\
6 \mathrm{~mm} \text { in size. }\end{array}$ \\
\hline Yeast-like growth & Light gray in color. \\
\hline
\end{tabular}

\begin{tabular}{|c|c|c|c|c|}
\hline \multirow[b]{2}{*}{ Patient } & \multicolumn{4}{|c|}{ Media } \\
\hline & $\begin{array}{l}\text { Blood Agar } \\
37^{\circ} \mathrm{C}\left(\mathrm{O}_{2} \text { rich }\right)\end{array}$ & $\begin{array}{l}\text { Chocolate Agar } \\
37^{\circ} \mathrm{C}\left(\mathrm{CO}_{2} \text { rich }\right)\end{array}$ & $\begin{array}{c}\text { Desoxycholate } \\
\text { Lactose Agar } \\
37^{\circ} \mathrm{C}\left(\mathrm{O}_{2} \text { rich }\right)\end{array}$ & $\begin{array}{c}\text { Sabouraud } \\
\text { Dextrose Agar } \\
25-30^{\circ} \mathrm{C}\left(\mathrm{O}_{2} \text { rich }\right)\end{array}$ \\
\hline 1 & - & - & - & \\
\hline 2 & - & +Yeast-like & - & $\times$ C. albicans \\
\hline 3 & + Strepts. & - & - & - \\
\hline 4 & - & - & - & - \\
\hline 5 & + S. aureus & + S. aureus & - & - \\
\hline 6 & - & - & - & - \\
\hline 7 & - & - & - & - \\
\hline 8 & + Strepts. & - & - & - \\
\hline 9 & - & - & - & - \\
\hline 10 & - & - & - & - \\
\hline 11 & - & - & - & - \\
\hline 12 & - & - & - & - \\
\hline 13 & - & - & - & - \\
\hline 14 & - & - & - & - \\
\hline 15 & - & - & - & - \\
\hline 16 & - & - & - & - \\
\hline 17 & - & - & - & - \\
\hline 18 & - & - & - & - \\
\hline 19 & - & - & - & - \\
\hline 20 & - & - & - & - \\
\hline 21 & - & - & - & - \\
\hline 22 & - & - & - & - \\
\hline 23 & - & - & - & - \\
\hline 24 & - & - & - & - \\
\hline 25 & - & - & - & - \\
\hline 26 & - & - & - & - \\
\hline 27 & + Strepts. & - & - & - \\
\hline 28 & - & - & - & - \\
\hline 29 & - & - & - & - \\
\hline 30 & & - & - & - \\
\hline
\end{tabular}

Table 1. Microbial activity after culturing, by patient and culture medium. Symbols and abbreviations: + means growth, - means no growth; $\mathrm{x}$ indicates late growth. Strepts = Streptococci spp, C. albicans = Candida albicans, $\mathrm{S}$. aureus $=$ Staphylococci aureus . 


\section{b. Microbial Susceptibility Analysis}

The human mouth can contain a large variety of microbes-as many as 31 distinct microbes have been reported [3]. More typically, 14 varieties make up the normal microbial flora of the mouth. In this study only four flourished on one or more of the different culture media after inoculation from mouthwash of patients with dental caries and incubation. These microbes were Streptococci spp, Staphylococci aureus, Candida albicans, and a yeast-like fungal specie. The number of plates on which they grew were relatively few, generally, and specifically minimal with respect to each specie.

Out of the 120 cultures only three were identified with growth of streptococci spp and all three cultures were on the Blood Agar media (see patients 3,8 and 27 of Table 1). Staphylococci aureus flourished in only two cultures (Blood Agar and Chocolate Agar. Candida albicans flourished on just one plate containing sabouraud dextrose agar. The yeast-like fungal growth survived and flourished on just one plate containing chocolate agar.

\section{CONCLUSIONS}

A very limited number of specimens showed microbial growth, and it is reasonable to suppose that the Newbouldia laevis mouthwash acted as a bactericide in the 113 cultures that showed no microbial growth. It therefore could be that a longer application period of the mouthwash (rinsing time) of 4 or 5 minutes might achieve complete inhibition. But we have not tested this hypothesis.

None of the cultured plates showed any evidence of lactobacilli, which have been implicated as the major dental caries causative bacteria. Also, Candida albicans, which causes oral thrush, was evident in only one plate.

We recognize that a more careful investigation must culture bacteria from patients' mouths after rinsing with sterile water but before rinsing with the mouthwash. That research remains for further investigation.

\section{ACKNOWLEDGEMENTS}

I owe the success of this work to God Almighty. I can never thank enough my darling Dad, Elder J. C. M. Okeke and darling Mum, Mother L. N. Okeke. I am equally thankful to the manager of City Health Laboratory Owerri, Mr. Tony Obasi, who supervised me during the laboratory investigation. To my lecturers at the Department of Botany, particularly Dr. E. Olapade and Dr. T. Fashola, I say a billion thanks. Finally I am indebted to the American Journal of Undergraduate Research for providing an avenue which encourages independent research and a forum for exchange of ideas for both American and foreign undergraduates.

\section{APPENDIX}

Materials used:

1. Sterile petri dishes

2. Autoclave (steam and pressure sterilizers)

3. Incubator

4. Wire loop (for inoculation)

5. Gram stain reagent set

6. Blood Agar Medium (B.A.)

7. Chocolate Agar Medium (C.A)

8. Desoxycholate lactose Agar Medium (D.C.A)

9. Sabouraud dextrose Agar Medium (S.D.A.)

10. Bunsen burner

11. Glass Slides (Clean, dry and grease free)

12. Microscope

13. Immersion oil

14. Distilled water

15. Anaerobic jar

\section{REFERENCES}

1. http://www.mobot.mobot.org/W3T/ Search/projs/Z11950.html

2. http://www.ansci.cornell.edu/plants/toxic agents/ betacarbolines/bcarbfams.html

3. I. Kroes, et al. "Bacterial Diversity Within the Human Subgingival Crevice," Proceedings of the National Academy of Sciences 1999 Dec 7:96 (25), pp.145471455. 